\title{
Effect of Varying Discharge Rate on the Performance of Venturi Aeration System
}

\author{
Anamika Yadav ${ }^{1, *}\left(\mathbb{D}\right.$, Avinash Kumar $^{1}$, Sudipto Sarkar ${ }^{1}$ \\ ${ }^{1}$ Assam University, Triguna Sen School of Technology, Department of Agricultural Engineering, Silchar, Assam, Pin- \\ 788011, India.
}

\section{How to cite}

Yadav, A., Kumar, A., Sarkar, S. (2022). Effect of Varying Discharge Rate on the Performance of Venturi Aeration System. Aquaculture Studies, 22(4), AQUAST824. http://doi.org/10.4194/AQUAST824

\section{Article History}

Received 17 November 2021

Accepted 22 Februrary 2022

First Online 23 February 2022

\section{Corresponding Author}

Tel.: +917987178532

E-mail: anamika.iit26@gmail.com

\section{Keywords}

Venturi

Standard aeration

Efficiency

Dissolved oxygen

Aeration

Aquaculture

\begin{abstract}
Venturi aeration is an economical method to increase dissolved oxygen (DO) in aquatic water bodies. For this paper, aeration experiments were conducted with 200 litres volume of the water tank, having dimensions of $90 \mathrm{~cm}$ length, $55 \mathrm{~cm}$ breadth, and 45 $\mathrm{cm}$ depth. The venturi was fabricated keeping the dimension of converging and diverging length same, i.e., $76 \mathrm{~mm}$ and throat length of $100 \mathrm{~mm}$. The venturi aeration system was operated with six different discharge rates $(0.00025,0.00033,0.00042$, $0.00050,0.00058$ and $0.00067 \mathrm{~m} 3 / \mathrm{s})$. This work is intended to estimate the effect of varying discharges on the efficiency of venturi aerator in terms of standard oxygen transfer rate (SOTR) and standard aeration efficiency (SAE). The experiment shows promising results in terms of SOTR and SAE at moderate to high discharge rates, on the other hand a declining trend is seen when the liquid discharge rate is too high. The oxygen transfer rate was found to have a good relationship with the discharge rate.
\end{abstract}

\section{Introduction}

Dissolved oxygen (DO) is one of the most essential component of water quality, it reflects the state of any water body's ecological health, and this is because aquatic life cannot survive if it's deprived of enough DO (Alison et al., 2010; Jayraj et al., 2017; Boyd, 2018; Roy et al., 2021). Aeration is very popular method and extremely useful in preserving the appropriate amount of DO in the semi-intensive and intensive aquaculture system (Boyd, 1998; Boyd \& McNevin, 2020; Roy et al., 2021). The aeration practice also gives a positive impact on efficacy of the aquaculture ecosystem and wastewater system (Rao et al., 2004; Baylar \& Ozkan, 2006). It is a versatile technique to remove the toxic gases $\left(\mathrm{H}_{2} \mathrm{~S}, \mathrm{CO}_{2}\right.$, and volatile organic matters) from water bodies and cumulatively improve the quality of water for the survival of aquatic animals (Boyle et al., 2002; Boyd, 1998). Sengupta \& Jana (1987) observed that the aerated tanks produced $25-82 \%$ more fish than non-aerated tanks. There are several reasons of supplementary benefits of an aerator to circulate water, such as, with flowing oxygenated water around all sections of pond, the fishes may find places of sufficient DO concentration more easily. For the maximum yield of aquaculture production, adequate design and layout are 
needed for the aerators, to have continuous and ample supply of DO to satisfy the demands of aquatic organisms (Soderberg, 2017; Cheng et al., 2019; Nguyen et al., 2020).

Venturi aeration is a well-known practice in the field of water engineering (Baylar \& Ozkan, 2006; Rathinakumar et al., 2014; Can et al., 2021). Venturi has a very simple structure, it mainly consists of three sections, converging (inlet), throat (middle constricted), and diverging section (outlet) shown in Figure 1. The converging section is an impressive section for converting the pressure head to velocity head. However, the diverging section alters the velocity head to pressure head. The venturi system generates a pressure difference that produces a vacuum at the throat section based on the working principle of Bernoulli's theorem (Baylar \& Ozkan, 2006). The principle of venturi has been in use in a variety of applications such as odor control, sludge digestion, wastewater aeration, lake stratification, seepage treatment, and measurements of air quality. The venturi is not only used in liquid alone but has numerous applications in gases and vapours as well (Wang \& Zhang, 1999). Venturi by far is most economical and cost-effective (Rathinakumar et al., 2014). Venturi aerators are highly effective and needs a differential of less than $20 \%$ to start suction (Ozkan et al., 2006a). There are numerous benefits of venturi aerators - (1) external power is not needed to operate, (2) its operating life is high, and (3) it is fail-proof because there is no moving parts- it is grossly maintenance-free. Mere simplicity, compact and adaptability of venturi are very attractive. The costeffective property of venturi makes it a ready replacement for other types of aerators. Bagatur (2005) worked on the disinfection of drinking water treatment using venturi aeration system, which stated that, the venturi device can be used to solve sour drinking water caused by hydrogen sulfide, excessive organic matter, nutrient, and nitrogen.

Venturi aeration has been used extensively as a method of aeration in the field of aquaculture (Baylar \&
Emiroglu, 2003; Baylar et al., 2005, Baylar et al., 2007; Baylar et al., 2010; Zhang, 2017; Chohan et al., 2017; Zhang et al., 2020; Xu et al., 2020) and wastewater treatment (Tchobanoglous et al., 2002; Gourich et al., 2007; West, 2009; Rosso et al., 2008) in recent years. Furthermore, other recent investigations have been conducted by the researchers who applied computational fluid dynamics (CFD) techniques to realize the principles of hydrodynamics (Kumar et al., 2014; Tamhankar et al., 2014; Tomov et al., 2015; Tukimin et al., 2016; Ande et al., 2018; Yin et al., 2018; Basso et al., 2019; Can et al., 2021). The venturi aeration system requires kinetic energy for increasing the air entrainment rate in the flowing water (Ozkan et al., 2006b). Mohammad et al., (2012) studied the effect of varying diverging angles on the flow velocity in the converging and diverging section. They have found that an increase in diverging angle increases the flow velocity in the converging section and reduces velocity in the diffuser. In terms of energy usage, venturi aeration systems are better than diffusers, but they suffer from a lower performance of standard oxygen transfer efficiency (Taricska et al., 2008). Susanto et al., (2021) studied on the comparative performance of stone diffuser with venturi skimmer. It was found that the venturi created fine air bubbles and the DO saturation was higher for venturi than stone diffuser.

Sanghani et al., (2016) assessed the effects on pressure drop in venturi through varying the geometric variables, i.e., converging and diverging angles, the diameter ratio, and the throat length. From the evaluation of various geometric variables of venturi, it was found that pressure drop varies with increasing inlet angle, outlet angle, and constricted section length. Gupta et al., (2016) studied the two-phase flow through the venturi. Several experiments were performed in multiphase loops with differing air-water flow rates to assess the pressure difference in venturi under twophase flow. It was discovered that a venturi would increase the void fraction exponentially up to $20 \%$, and that this is feasible in a flow regime with a precision of 5
Converging Section

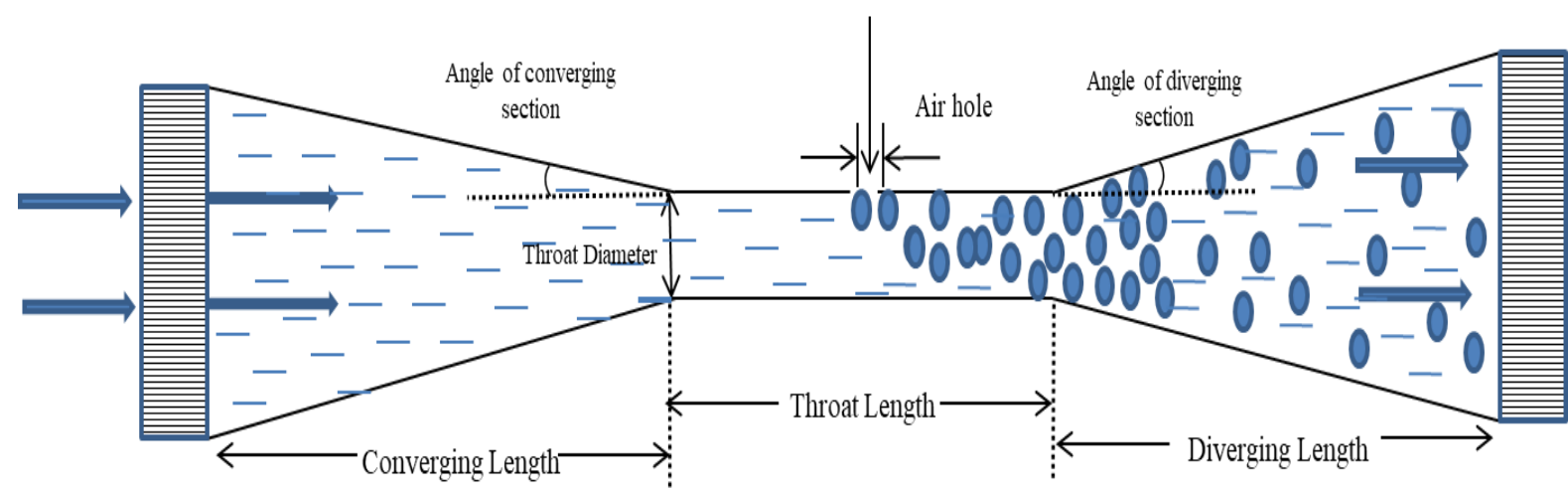

Figure 1. Schematic view of the venturi device. 
$\%$. This may be due to the difference in the flow mechanism and turbulent forces that affect the momentum of flow in the venturi (Gupta et al., 2016). Bunea \& Ciocan (2018) investigated the efficiency of oxygen transfer from air to water in comparison to the energy used by air injection to optimize two major parameters: aeration efficiency and energy consumption in air entrainment. Mahmud et al., (2020) proposed to increase aeration performance by recirculating water from a river using a venturi aspirator through the piping networking. They have concluded that the venturi aspirator aerator is feasible in the field of aquaculture and wastewater treatment industries. Recently the circular fish tank operated using venturi aeration by author Zhang et al., (2020). It was obtained from the results that the maximum standard aeration efficiency (SAE) values produced from 1.7 to $2.05 \mathrm{~kg}$ $\mathrm{O}_{2} / \mathrm{kWh}$. The authors have concluded that the venturi aeration system saves energy and is economically adoptable.

Most of the previous studies focus on the design parameters of venturi, whereas the information on the effect of operating conditions such as discharge or flow is very limited. However, the systematic and specific operational conditions are of much importance to get maximum profit from the aquaculture farms. The aim of the present study is to determine the effect of varying discharge rates on the performance of venturi aeration systems. In the present study, the geometrical parameters of venturi have been selected from the previous study of Yadav et al., (2021) to see the effect of dynamic parameter such as discharge rate. The details of the geometrical parameters of venturi are presented in Table 1.

\section{Materials and Methods}

\section{Experimental Set-up}

The experimental setup contains a water tank, pump, venturi, valves, water meter, and pipe accessories to make the water circulation in a closedloop as shown in Figure 2. The experimental setup having the dimension of $90 \mathrm{~cm} \times 55 \mathrm{~cm} \times 45 \mathrm{~cm}$ (length $\times$ breadth $\times$ depth), in which the aeration experiments were performed with total 200 litres volume of water. A 1.02 HP axial flow pump manufactured by Kirloskar Brothers Limited, Coimbatore, India was used to carry out the experiments over the venturi aeration system. The venturi device was fabricated from the Santra Engineering Workshop, Kolkata (W.B.), India. The converging and diverging sections' length and diameter are selected having same value, i.e., $76 \mathrm{~mm}$ and $60 \mathrm{~mm}$ respectively. The converging and diverging angles are kept similar as $15^{\circ}$ throughout the experiments (Yadav et al., 2021). A total 17 number of air holes of $2 \mathrm{~mm}$ diameter were uniformly distributed over $100 \mathrm{~mm}$ throat length. Threads are provided at both sides of the converging and diverging section for easy connection and dismantling with the pipe. In the present study, the mixture of air bubbles and water comes out from the venturi directly on the surface of water at a low height

Table 1. The geometric parameters of venturi aeration system (Yadav et al., 2021)

\begin{tabular}{lcc}
\hline S. No. & Geometric Parameter & Optimum Values \\
\hline 1. & Converging and diverging angle $(\alpha$ and $\beta)$ & $15^{\circ}$ \\
2. & Throat length $\left(\mathrm{t}_{\mathrm{l}}\right)$ & $100 \mathrm{~mm}$ \\
3. & Number of air hos $(\mathrm{N})$ & 17 \\
\hline
\end{tabular}

Table 2. Schedule of experiments to determine the effects of varying discharge rate on the performance of venturi aeration

\begin{tabular}{llcc}
\hline S. No. & $\mathrm{Q}\left(\mathrm{m}^{3} / \mathrm{s}\right)$ & Constants & Total number of experiments \\
\hline 1. & 0.00025 & & \\
2. & 0.00033 & & \\
3. & 0.00042 & Selected geometric parameters of venturi: $\mathrm{t}_{1}, \mathrm{~N}$, and $\alpha$ and $\beta$ & \\
4. & 0.00050 & & \\
5. & 0.00058 & & \\
6. & 0.00067 & & \\
\hline
\end{tabular}

Table 3. Value of SOTR per unit discharge for different experiments

\begin{tabular}{ccccc}
\hline S. No. & Discharge $\left(\mathrm{m}^{3} / \mathrm{s}\right)$ & $\mathrm{K}_{\mathrm{L}} \mathrm{a}_{20}\left(\mathrm{~h}^{-1}\right)$ & SOTR $\left(\mathrm{kg} \mathrm{O}_{2} / \mathrm{h}\right)$ & SOTR per unit discharge $\left(\mathrm{kg} \mathrm{O}_{2} / \mathrm{m}^{3}\right)$ \\
\hline 1. & 0.00025 & 1.642 & 0.00298 & 0.00330 \\
2. & 0.00033 & 2.240 & 0.00408 & 0.00341 \\
3. & 0.00042 & 2.933 & 0.00532 & 0.00352 \\
4. & 0.00050 & 3.601 & 0.00654 & 0.00363 \\
5. & 0.00058 & 4.558 & 0.00827 & 0.00396 \\
6. & 0.00067 & 5.110 & 0.00927 & 0.00384 \\
\hline
\end{tabular}


(less than $1 \mathrm{~m}$ ), which creates a ripple effect on the water surface rather than the wave generation. Therefore, the atmospheric oxygen mass transfer from water surface due to agitation (due to ripple effect) was ignored since the mentioned effect is similar on all the experimental groups.

\section{Aeration Test and Performance}

The present study has been carried out with unsteady-state conditions using clean tap water (ASCE, 2007). The oxygen mass transfer rate starts from the atmosphere to the liquid through the gas-liquid interface followed by the laminar flow along both sides of the gas-liquid interface established by the two-film theory of oxygen mass transfer (Lewis \& Whitman, 1924) and can be expressed as follows:

$$
\frac{d C}{d t}=K_{L}\left(\frac{A}{V}\right)\left(C_{s}-C_{m}\right)
$$

where, $\frac{\mathrm{dc}}{\mathrm{dt}}$ is the oxygen transfer rate between the gas and liquid $(\mathrm{mg} / \mathrm{l} / \mathrm{s}), \frac{\mathrm{A}}{\mathrm{V}}$ is the ratio of the air-water interfacial area to water volume $\left(\mathrm{m}^{-1}\right), K_{L}$ is the liquidfilm coefficient $\left(\mathrm{h}^{-1}\right), \quad \mathrm{C}_{\mathrm{s}}$ is saturation oxygen concentration $(\mathrm{mg} / \mathrm{l})$ and $\mathrm{C}_{\mathrm{m}}$ is the measured oxygen concentration $(\mathrm{mg} / \mathrm{l})$.

Boyd \& Ahmad (1987) evaluated the standard oxygen transfer rate (SOTR) and standard aeration efficiency (SAE) through different types of aerators used in aquaculture ponds. The SAE value and durability of the aeration system are most important during the selection of an aerator for day-to-day use in aquaculture ponds. Alternatively, high SOTR values and flexibility are significant for aerators used to save the aquatic species in difficult situations. The SOTR is specified as the amount of oxygen that the aerator can introduce into a body of water per unit time at standard conditions, i.e., water temperature $20{ }^{\circ} \mathrm{C}$, initial DO concentration 0 $\mathrm{mg} / \mathrm{l}$, one atmospheric pressure, and clear tap water (APHA, 1985).

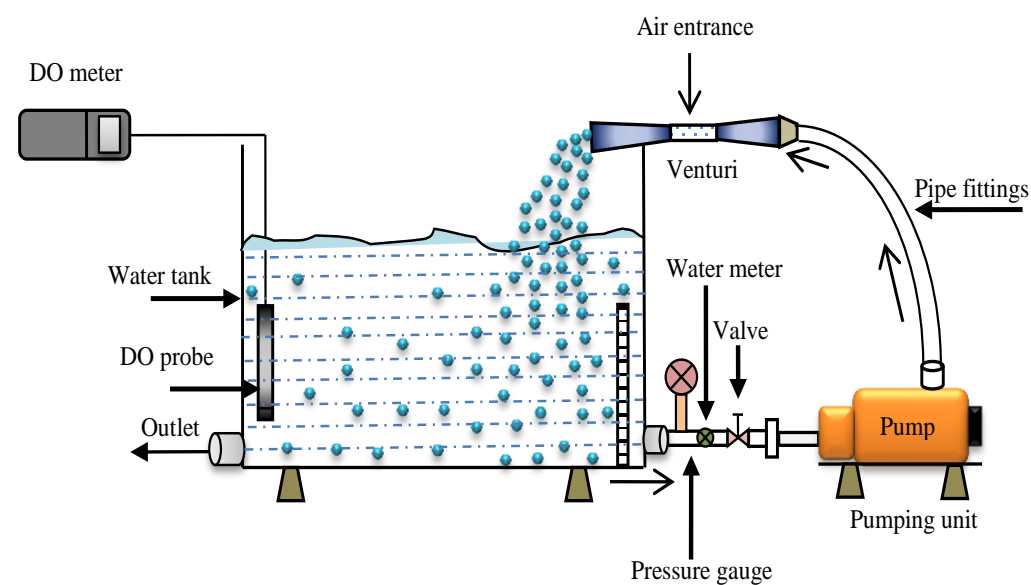

Figure 2. Experimental setup.

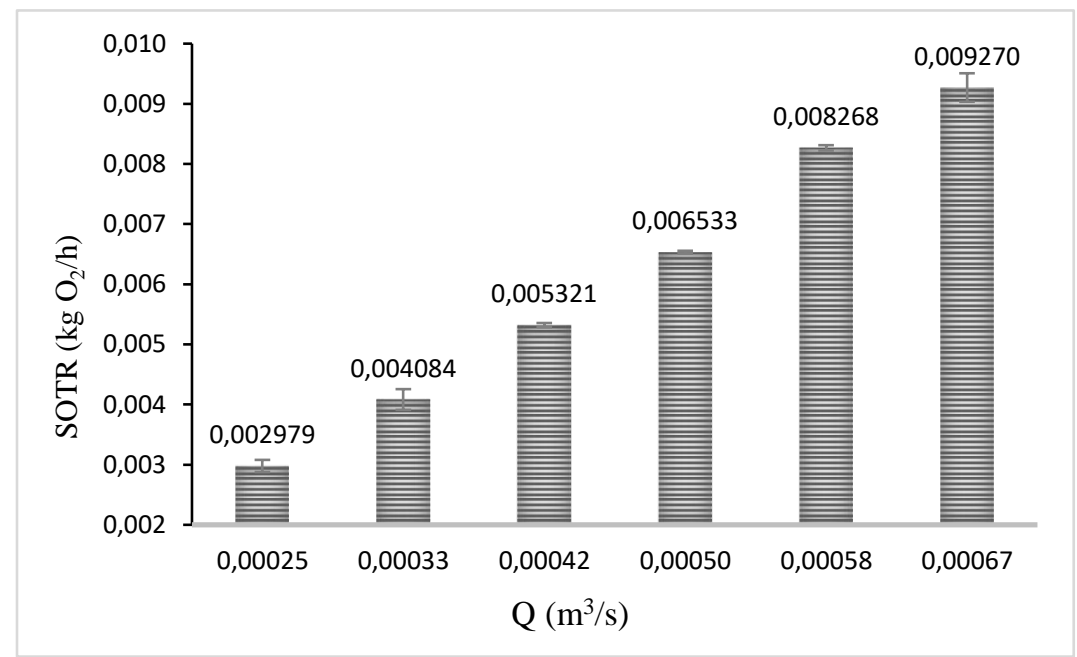

Figure 3. Variation of SOTR with varying discharge. 


$$
\text { SOTR }=K_{L} a_{20} \times\left(C_{s}-C_{0}\right) \times V \times 10^{-3}
$$

where, SOTR is the standard oxygen transfer rate $(\mathrm{kg} \mathrm{O} / \mathrm{h}), \quad \mathrm{C}_{\mathrm{S}}$ is the saturation value of $\mathrm{DO}$ at test conditions $(\mathrm{mg} / \mathrm{l}), \mathrm{C}_{0}$ is the DO concentration at time $\mathrm{t}$ $=0(\mathrm{mg} / \mathrm{l}), \mathrm{V}$ is the volume of the water tank $\left(\mathrm{m}^{3}\right)$, and $\mathrm{K}_{\mathrm{L}} \mathrm{a}_{20}$ is the standard oxygen transfer coefficient at temperature $20^{\circ} \mathrm{C}\left(\mathrm{h}^{-1}\right)$.

$$
K_{L} a_{20}=K_{L} a_{T} \times \theta^{(20-T)}
$$

where, $\mathrm{K}_{\mathrm{L}} \mathrm{a}_{\mathrm{T}}$ is the oxygen transfer coefficient at temperature $\left({ }^{\circ} \mathrm{C}\right)$, and $\theta$ is 1.024 for clean tap water (Boyd, 1998; ASCE, 2007).

The SAE value of an aerator gives a relation between SOTR and the power used to operate the system (Lawson \& Merry, 1993).

$$
S A E=\frac{S O T R}{P}=\frac{K_{L} a_{20} \times\left(C_{S}-C_{0}\right) \times V \times 10^{-3}}{P}
$$

where, SAE is the standard aeration efficiency ( $\mathrm{kg}$ $\left.\mathrm{O}_{2} / \mathrm{kWh}\right)$, and $\mathrm{P}$ is the power input (kW).

The brake power $(P)$ in kW is estimated using the following Eq. 5 (Kumar et al., 2013)

$$
P=\frac{(9.81 \times Q \times H)}{\eta}
$$

where, $Q$ is the pump discharge $\left(\mathrm{m}^{3} / \mathrm{s}\right), \mathrm{H}$ is the total dynamic head $(m)$, and $\eta$ is the mechanical efficiency of the pump (\%).

The functional relationship between $S A E / \triangle C$ and the key variables such as geometric, dynamic and physical parameters can be expressed as in Eq. 6:

$$
\frac{S A E}{\Delta C}=f_{1}\left(t_{l}, t_{d}, t_{h}, N, \alpha, \beta, V, \rho_{a}, \rho_{w}, g, v_{w}, \sigma_{w}, v_{w}\right)
$$

where, $t_{l}$ is the throat length $(\mathrm{m}), t_{d}$ is the throat diameter $(\mathrm{m}), t_{h}$ is the throat hole diameter $(\mathrm{m}), N$ is the number of air holes, $\alpha$ is the converging angle $\left({ }^{\circ}\right), \beta$ is the diverging angle $\left({ }^{\circ}\right), \rho_{a}$ is the density of air $\left(\mathrm{kg} / \mathrm{m}^{3}\right)$, $\rho_{w}$ is the mass density of water $\left(\mathrm{kg} / \mathrm{m}^{3}\right), \mathrm{g}$ is the acceleration due to gravity $\left(\mathrm{m} / \mathrm{s}^{2}\right), v_{w}$ is the flow velocity $(\mathrm{m} / \mathrm{s}), \sigma_{w}$ is the surface tension of water $(\mathrm{N} / \mathrm{m}), v_{w}$ is the kinematic viscosity of water $\left(\mathrm{m}^{2} / \mathrm{s}\right)$, and $\Delta C$ is the oxygen deficit $(\mathrm{mg} / \mathrm{l})$.

From the dimensional analysis of the Eq. 6 using Buckingham $\Pi$ theorem, the non-dimensional form of standard aeration efficiency (NDSAE), Reynolds number (Re) and Froude Number (Fr) can be estimated using Eq. 7, Eq. 8, and Eq. 9 respectively.

$$
\begin{aligned}
& N D S A E=(S A E / \triangle C) \rho_{w} v_{w}^{2} \\
& \operatorname{Re}=\frac{v_{w}}{t_{l} v_{w}}
\end{aligned}
$$

$$
F r=\frac{g t_{l}}{v_{w}^{2}}
$$

\section{Experimental Procedure}

The experiments were started by deoxygenating a basin of clean tap water. The deoxygenation process was carried out by using sodium sulphite $(10 \mathrm{mg} / \mathrm{l})$ as a deoxygenating agent, and cobalt chloride $(0.1 \mathrm{mg} / \mathrm{l})$ as a catalyst for each $\mathrm{mg} / \mathrm{l}$ of DO present in the water (Ahmad \& Boyd, 1988; Jayraj et al., 2017; Baylar et al., 2006; Baylar et al., 2007). With the start of the venturi operation, DO concentration starts rising and measurements were taken at equal time intervals till DO concentration rises from approximately $0 \mathrm{mg} / \mathrm{l}$ to about $80 \%$ of saturation. The DO and temperature of the water during the experiments were measured with the help of a DO meter (Model: EXTECH DO meter, YSI Professional Plus). The flow rates of water during the experiments were measured by using a water meter (Hach Hydrolab Sonde DS5). All experimental readings were taken continuously at equal intervals. The performance of the venturi aeration system was evaluated in terms of SOTR and SAE at different discharge rates using the Eq. 2 and Eq. 4 respectively. Further, based on the results obtained, the NDSAE, Reynolds number, and Froude number were also calculated using the Eq. 7, 8 and 9 respectively. The schedule of experiments to determine the effects of varying discharge rates on the performance of venturi are shown in Table 2. All the experiments were conducted with three replications by varying the discharge rate ranges from 0.00025 to $0.00067 \mathrm{~m}^{3} / \mathrm{s}$.

\section{Results and Discussion}

\section{Effect of Discharge on the SOTR and SAE}

The effect of discharge on the performance of the venturi aeration was analysed based on SOTR and SAE. Variations of SOTR and SAE for different discharge rates are shown in Figure 3 and Figure 4 respectively. It can be seen from Figure 3 that the value of SOTR increases with increasing the discharge rate. The values of $\mathrm{K}_{\mathrm{L}} \mathrm{a}_{20}$ and SOTR unit discharge are presented in Table 3. The maximum SOTR value was obtained $0.00927 \mathrm{~kg} \mathrm{O} / \mathrm{h}$ at the maximum discharge rate. The SOTR value varies from 0.00298 to $0.00927 \mathrm{~kg} \mathrm{O} / \mathrm{h}$ by varying discharge rates from 0.00025 to $0.00067 \mathrm{~m}^{3} / \mathrm{s}$. This is because an increase in molecular diffusion at high discharge, the rate of exchange of gas between liquid film and gas film increases and consequently facilitates higher air entrainment through the air holes present at the throat of the venturi.

Furthermore, the SAE values were calculated at different discharge rates as per the schedule of experiments from Table 2. The SAE value increases with increasing the discharge rates, but the values diminish if the discharge rate is too high. The SAE values raise 
approximately $20 \%$ with increasing discharge rate from 0.00025 to $0.00058 \mathrm{~m}^{3} / \mathrm{s}$. However, for discharge rate from 0.00058 to $0.00067 \mathrm{~m}^{3} / \mathrm{s}$ about a $3 \%$ fall was observed in SAE value.

The maximum value of SAE $0.504 \mathrm{~kg} \mathrm{O}_{2} / \mathrm{kWh}$ was found at the discharge rate of $0.00058 \mathrm{~m}^{3} / \mathrm{s}$. This was specifically due to the rise in the rate of gas exchange between a liquid and a gas film which attributed in particular to the enhanced pressure difference caused due to the molecular turbulence. The mean comparison of SOTR and SAE values for different discharge rates by Duncan's test $(P<0.05)$ are presented in Table 4 . The mean, standard deviation, and coefficient of variance of SOTR were calculated to be $0.00243 \mathrm{~kg} \mathrm{O}_{2} / \mathrm{h}, 0.00608 \mathrm{~kg}$ $\mathrm{O}_{2} / \mathrm{h}$, and $39.87 \%$ respectively. Thus, the corresponding SAE values of the respective mean, standard deviation, and coefficient of variance were calculated as $0.0320 \mathrm{~kg}$ $\mathrm{O}_{2} / \mathrm{kWh}, 0.460 \mathrm{~kg} \mathrm{O}_{2} / \mathrm{kWh}$, and $69.69 \%$ respectively.

\section{Variation of NDSAE with Re and Fr at Varying Discharge Rates}

Figure 5 depicts a schematic plot of NDSAE and Re for various discharge rates of the venturi aeration system. It can be observed from Figure 5 that the entire collection of data points developed a single curve by each discharge. The relation between NDSAE and Re of venturi at varying discharge rates can be closely fitted by a power function of the following form with a coefficient of determination $\left(R^{2}\right)$ equal to the value of 0.99 .

$$
N D S A E=1 E-13 \times R e^{2.178}
$$

It can be observed that the Re value decreases with increasing NDSAE presented in Table 5 . The maximum Re value was obtained $3.689 \times 10^{-5}$ at the lowest NDSAE value of $0.620 \times 10^{-3}$. The minimum $\operatorname{Re}$ value was

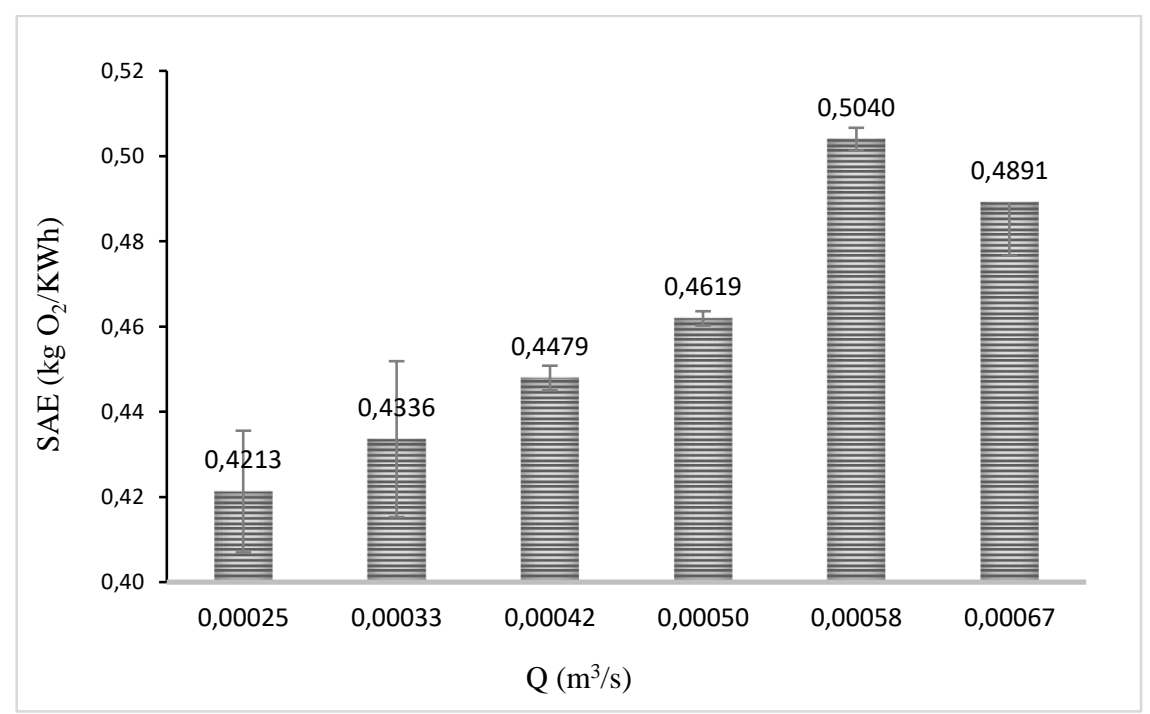

Figure 4. Variation of SAE with varying discharge.

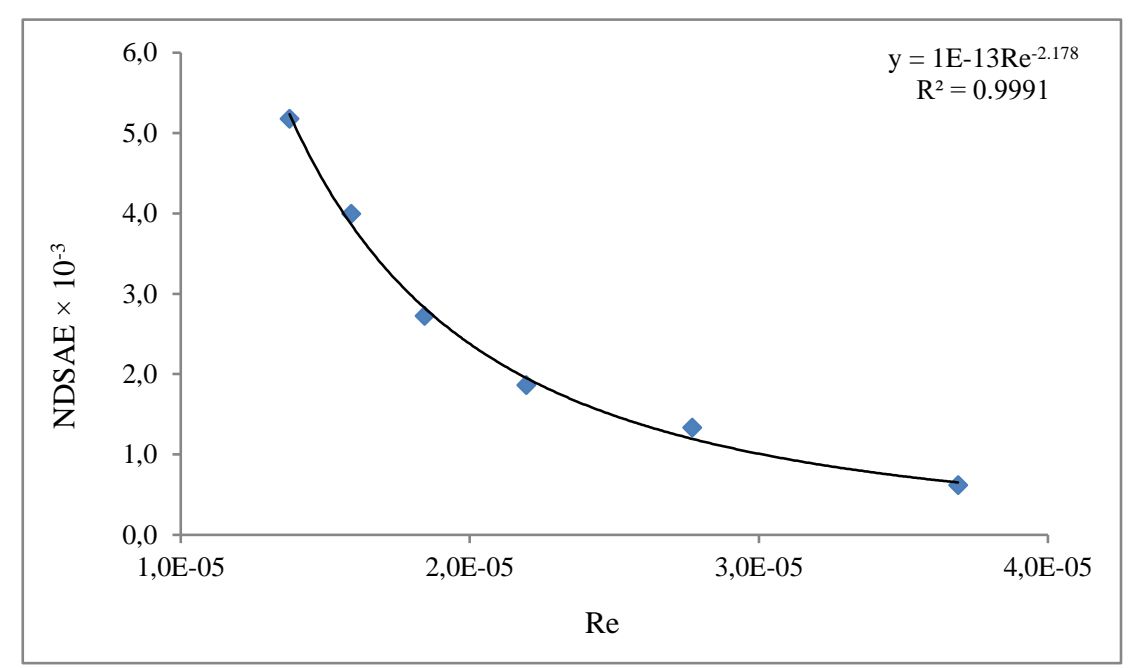

Figure 5. Variation of NDSAE with Re for different discharge rates. 
obtained $1.377 \times 10^{-5}$ at the highest NDSAE value of $5.175 \times 10^{-3}$. This is because of the kinetic energy of air entrainment into the flowing water produces concentrated disturbances and mingling with the bulk liquid through venturi, thus air diffusion is formed, similar effect was found by authors Xu et al., (2020). Therefore, as a result, it can say that, the converging angle and diverging angle of venturi are more responsive to establish a good connection between air entrainment and turbulent flow. As NDSAE is a property of discharge (Q) and $S A E$, the values of $Q$ influence the SAE values. It does not imply a rise in NDSAE in terms of $S A E$. It relies only on the value of $Q$. For a specific value of NDSAE, the value of SAE can be increased by increasing the value of $Q$.

As seen in Figure 6, a related procedure was used to determine the relationship between NDSAE and Fr. In venturi aeration, NDSAE was established to have a substantial relationship with Fr. Figure 6 shows that the whole range of data points produces a single curve by each discharge value, which is same as above. The relation between NDSAE and Fr can also be equipped by a power function of the following form with a coefficient of determination $\left(R^{2}\right)$ equal to the value of 1 (Figure 6 ).

$$
N D S A E=0.0163 \times F r^{-1.089}
$$

The values of Fr decreases with increasing NDSAE values presented as shown in Table 5 . The highest value of Fr was obtained as 20.40 at the lowest NDSAE value of $0.620 \times 10^{-3}$. However, it is well known that NDSAE is a function of $Q$ and $S A E$, and the $Q$ values can influence the SAE values. Hence, the Fr can also be a function of $Q$. The Fr values decrease with increasing discharge. The reason behind this is the gravitational acceleration with the supercritical flow conditions discovered at the throat section of the venturi. Hence, very rapid and fast flow conditions were measured at the converging section towards throat section of the venturi. Due to the disturbances of air-water flow from throat section to the

Table 4: Mean comparison of SOTR and SAE values for different discharge rates by Duncan's test $(p<0.05)$

\begin{tabular}{|c|c|c|c|c|}
\hline S. No. & $\mathrm{Q}\left(\mathrm{m}^{3} / \mathrm{s}\right)$ & Replications & SOTR mean \pm SD & SAE mean \pm SD \\
\hline & & R1 & & \\
\hline \multirow[t]{3}{*}{1} & 0.00025 & $\mathrm{R} 2$ & $0.00298^{a} \pm 0.0001$ & $0.4213^{a} \pm 0.0143$ \\
\hline & & R3 & & \\
\hline & & $\mathrm{R} 1$ & & \\
\hline \multirow[t]{3}{*}{2} & 0.00033 & $\mathrm{R} 2$ & $0.00406^{b} \pm 0.0001$ & $0.4336^{\mathrm{ab}} \pm 0.0183$ \\
\hline & & R3 & & \\
\hline & & $\mathrm{R} 1$ & & \\
\hline \multirow[t]{3}{*}{3} & 0.00042 & $\mathrm{R} 2$ & $0.00532^{c} \pm 0.00003$ & $0.4479 b c \pm 0.0029$ \\
\hline & & R3 & & \\
\hline & & $\mathrm{R} 1$ & & \\
\hline \multirow[t]{3}{*}{4} & 0.00050 & $\mathrm{R} 2$ & $0.00653^{d} \pm 0.00002$ & $0.4619^{c} \pm 0.0017$ \\
\hline & & R3 & & \\
\hline & & $\mathrm{R} 1$ & & \\
\hline \multirow[t]{3}{*}{5} & 0.00058 & $\mathrm{R} 2$ & $0.00827^{e} \pm 0.00004$ & $0.5040^{d} \pm 0.0027$ \\
\hline & & R3 & & \\
\hline & & $\mathrm{R} 1$ & & \\
\hline \multirow[t]{2}{*}{6} & 0.00067 & $\mathrm{R} 2$ & $0.00927^{f} \pm 0.0002$ & $0.4892^{d} \pm 0.0125$ \\
\hline & & R3 & & \\
\hline
\end{tabular}

*Data are presented as mean \pm standard deviation. $n=3$, Mean values in the same column with different superscripts $(a, b, c, d, e, f)$ are significantly different ( $p<0.05) ; R 1, R 2$, and R3 are the replications of each discharge rate of the experiment.

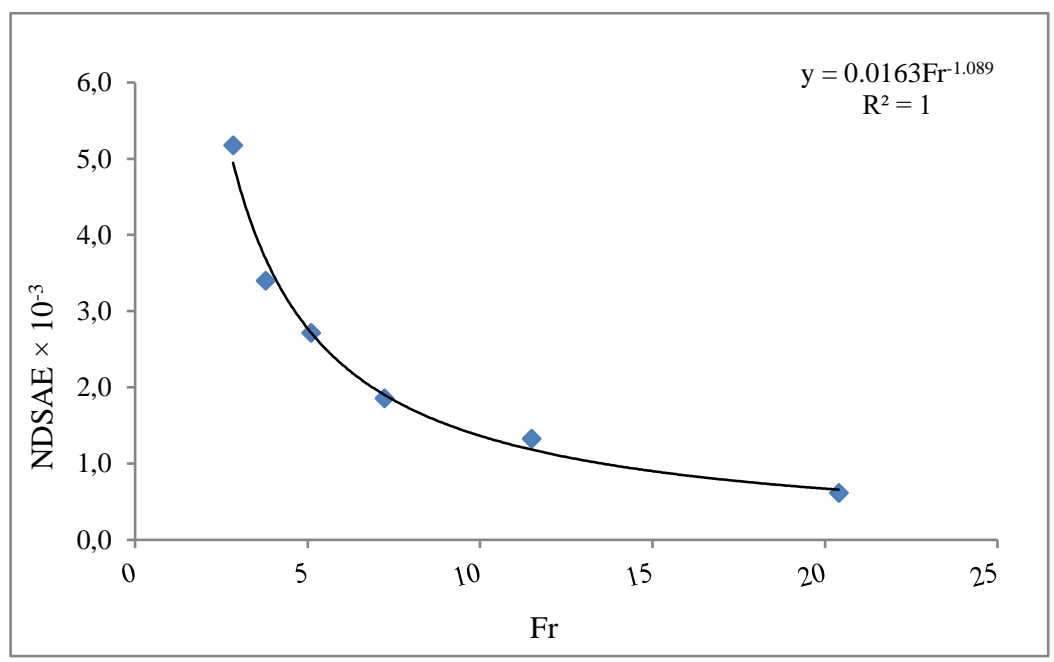

Figure 6. Variation of NDSAE with Fr for different discharge rates. 
diverging section, the air bubbles expand, and their surface area increases. As a result, Fr can be useful in determining circumstances in which surface undulation can lead to the rate of air entertainment (Campbell, 2015; Yadav et al., 2021).

\section{Conclusion}

From the overall experimental results, it was found that the discharge plays an important role in contributing to the higher yield of aeration efficiency of the venturi aeration system. The value of SOTR and SAE increases with raising the discharge rate throughout the experiments. However, the SAE value reaches the highest range and then decreases with further increasing discharge rate. The values of Reynolds number and Froude number often rely on the discharge. However, the aeration performance can be significantly improved by the Reynolds number and Froude number values. Thus for the specific optimized geometric parameters of venturi, the optimum value of discharge was found to be $0.00058 \mathrm{~m}^{3} / \mathrm{s}$. From the results of this study, it can be concluded that the discharge rate is the most significant dynamic parameter to increasing the overall efficiency of the venturi aeration system. Thus, it can say that, after the geometrical parameters of venturi, the dynamic parameter, i.e., discharge rate is also the main point of consideration during the design of a venturi aeration system.

\section{Ethical Statement}

Not applicable.

\section{Funding Information}

No funding was taken from external agency.

\section{Author Contribution}

A.Y. planned the experiments, performed the experiments, and measurement, data analysis, and manuscript preparation- review and writing. A.K. is the co-supervisor and participated to data analyses, manuscript preparation reviewing and editing work. S.S. is the supervisor and provided support for manuscript preparation, reviewing and editing work. All authors read and approved the final manuscript.

\section{Conflict of Interest}

The authors declare that they have no conflict of interest.

\section{References}

Ahmad, T., \& Boyd, C.E. (1988). Design and performance of paddlewheel aerators. Aquaculture Engineering, 7(1), 39-62. https://doi.org/10.1016/0144-8609(88)90037-4
Alison, J., Smith, L., \& Delorme, D. (2010). Ecology and classification of North American freshwater invertebrates. $3^{\text {rd }}$ ed., Academic Press. ISBN: 978-0-12374855-3.

Ande, R., \& Yerraboina, V.N.K. (2018). Numerical investigation on the effect of divergent angle in convergent-divergent rocket engine nozzle. Chemical Engineering Transactions, 66, 787-792. https://doi.org/10.3303/CET1866132

APHA (1985). Standard methods for the examination of water and wastewater. American water works association and water pollution control federal. $16^{\text {th }}$ ed., American Public Health Association, Washington, DC.

ASCE (2007). Standard measurement of oxygen transfers in clean water. American Society of Civil Engineers, Virginia.

Bagatur, T. (2005). Minimal conditions for venturi aeration of water flows. Proceedings of the Institution of Civil Engineers-Water Management, 158(3), 127-130. https://doi.org/10.1680/wama.2005.158.3.127

Basso, A., Hamad, F.A., \& Ganesan, P. (2019). Initial Results from the Experimental and Computational Study of Microbubble Generation. Proceedings of the $4^{\text {th }}$ World Congress on Momentum, Heat and Mass Transfer (MHMT'19) Rome, Italy, Paper No. ICMFHT 101.

Baylar, A., \& Emiroglu, M. (2003). Air entrainment and oxygen transfer in a venturi. Proceedings of the ICE Water and Maritime Engineering, 156(3), 249-255. https://doi.org/10.1680/wame.2003.156.3.249

Baylar, A., Ozham, F., \& Unsal, M. (2007). Determination of the optimal location of the air hole in venturi aerators. Clean-soil Air Water, 35(3), 246-249. https://doi.org/10.1002/clen.200700026

Baylar, A., Ozkan, F., \& Ozturk, M. (2005). Influence of venturi cone angles on jet aeration systems. Process Institute of Civil Engineering-Water Management, 158, 9-16. https://doi.org/10.1680/wama.2005.158.1.9

Baylar, A., Ozkan, F., \& Tugal, M. (2006). The Performance of two-phase flow systems in pond aeration. International Journal of Science \& Technology, 1(1), 65-74.

Baylar, A., Ozkan, F., \& Unsal M. (2010). Effect of air inlet hole diameter of venturi tube on air injection rate. KSCE Journal of Civil Engineering, 14(4), 489-492. https://doi.org/10.1007/s12205-010-0489-6

Boyd, C.E., \& McNevin, A.A. (2020). Aerator energy use in shrimp farming and means for improvement. Journal of World Aquaculture Society, 1-24. 10.1111/jwas.12753

Boyd, C.E. (1998) Pond water aeration systems. Aquacultural Engineering, 18(1), 9-40. https://doi.org/10.1016/S0144-8609(98)00019-3

Boyd, C.E., \& Ahmad, T. (1987). Evaluation of aerators for channel catfish farming. Bulletin 584, Alabama Agricultural Experiment Station, Auburn University, Alabama, PP. 52. ISSN : 0271-0544

Boyle, W.C., Mueller, J.A., \& Popel, H.J. (2002). Aeration: practices and principles. $1^{\text {st }}$ ed., London: CRC Press.

Bunae, F., \& Ciocan, G.D. (2018). Experimental study of standard aeration efficiency in a bubble column. Environmental Science, 350-367. 10.5772/intechopen.76696

Campbell, J. (2015). Complete casting handbook metal casting processes, metallurgy, techniques and design. $2^{\text {nd }}$ ed., Fluids. ISBN 978-0-444-63509-9.

Can, O.F., Bagatur, T., \& Çelik, N. (2021). Numerical and experimental investigation of air injection process with 
venturi pipe part. $5^{\text {th }}$ International Anatolian Energy Symposium, Karadeniz Technical University, Trabzon/Turkey, 103-114.

Cheng, X., Xie, Y., Zhu, D., \& Xie, J. (2019). Modeling reoxygenation performance of fine-bubble-diffusing aeration system in aquaculture ponds. Aquaculture International, 27(5), 1353-1368. https://doi.org/10.1007/s10499-019-00390-6

Chohan, M.I., Hussain, T., \& Tunio, I. (2017). Influence of convergent section length and angle on performance of supersonic nozzle. Sindh University Research Journal (Science Series), 49(4), 727-732.

Gourich, B., El-Azher, N., Vial, C., \& Belhaj, M. (2007). Influence of operating conditions and design parameters on hydrodynamics and mass transfer in emulsion loopventuri reactor. Chemical Engineering and Processing, 46(2), 139-149.

https://doi.org/10.1016/j.cep.2006.05.006

Gupta, B., Nayak, A.K., Kandar, T.K., \& Nair, S. (2016). Investigation of air-water two phase flow through a venturi. Experimental Thermal and Fluid Science, 70, 148-154. https://doi.org/10.1016/j.expthermflusci.2015.07.012

Jayraj, P., Roy, S.M., Mukherjee, C.K., \& Mal, B.C. (2017) Design Characteristics of Submersible Aerator. Turkish Journal of Fisheries and Aquatic Sciences, 18(9). 10.4194/13032712-v18_9_01

Kumar, A., Moulick, S., \& Mal, B.C. (2013). Selection of aerators for intensive aquacultural pond. Aquacultural Engineering, 56, 71-78. https://doi.org/10.1016/j.aquaeng.2013.05.003

Kumar, J., Singh, J., Kansal, H., Narula, G.S., \& Singh, P. (2014). CFD analysis of flow through venturi. International Journal of Research in Mechanical Engineering \& Technology, 4(2), 214-217. ISSN : 2249-5762

Lawson, T.B., \& Merry, G.E. (1993). Procedures for evaluating low-power surface aerators under field conditions. In: Techniques for Modern Aquaculture (Ed. Wang, J.K.), Proceedings of an Aquacultural Engineering Conference, ASAE, Michigan, USA, 511.

Lewis, W.K., \& Whitman, W.G. (1924). Principles of gas absorption. Industrial and Engineering Chemistry Research, 16(12), 1215-1220.

Mahmud, R., Erguvan, M., \& MacPhee, D.W. (2020). Performance of closed loop venturi aspirated aeration system: experimental study and numerical analysis with discrete bubble model. Water, 2(6), 1637. https://doi.org/10.3390/w12061637

Mohammad, M., Maryam, A., \& Amirhosein, A. (2012). Study on the variation effects of diverging angle on characteristics of flow in converging and diverging ducts by numerical method. World Academy of Science, Engineering and Technology, 6(7), 1-5. doi.org/10.5281/zenodo.1331903

Nguyen, N.T., Matsuhashi, R., \& Vo-Chau, T.T.B. (2020). A design on sustainable hybrid energy systems by multiobjective optimization for aquaculture industry. Renew Energy, 163:1878-1894. https://doi.org/10.1016/j.renene.2020.10.024

Ozkan, F., Baylar, A., \& Tugal, M. (2006a). The performance of two phase flow systems in pond aeration. International Journal of Science and Technology, 1(1), 65-74.

Ozkan, F., Ozturk, M., \& Baylar, A. (2006b). Experimental investigations of air and liquid injection by venturi tubes.
Water and Environment Journal, 20(3), 114-122. https://doi.org/10.1111/j.1747-6593.2005.00003.x

Rao, A.R., Laxmi, B.V.B., \& Narasiah, K.S. (2004). Simulation of oxygen transfer rates in circular aeration tanks. Water Quality Research Journal Canada, 39(3), 237-244 https://doi.org/10.2166/wqrj.2004.033

Rathinakumar, V., Dhinakaran, G., \& Suribabu, C.R. (2014). Assessment of aeration capacity of stepped cascade system for selected geometry. International Journal of Chemical Technology and Research, 6(1), 254-262.

Rosso, D., Larson, L., \& Stenstrom, M. (2008). Aeration of large municipal wastewater treatment plants: state of the art. Water Science and Technology, 57(7), 973-978. 10.2166/wst.2008.218

Roy, S.M., Jayraj, P., Machavaram, R., \& Mal, B.C. (2021) Diversified aeration facilities for effective aquaculture systems-a comprehensive review. Aquaculture International, 29, 1181-1217. https://doi.org/10.1007/s10499-021-00685-7

Sanghani, C.R., Jayani, D.C., Jadvani, N.R., Dobariya, H.N., \& Jasoliya, K.R. (2016). Effect of Geometrical Parameters of Venturi meter on Pressure Drop. International Journal of Scientific Research in Science, Engineering and Technology, 2(2), 865-868.

Sengupta, S., \& Jana, B.B. (1987). Effect of aeration on the primary productivity of phytoplankton in experimental tanks. Aquaculture, 62(2), 131-141. https://doi.org/10.1016/0044-8486(87)90317-6

Soderberg, R. (2017). Aquaculture technology: flowing water and static water fish culture. CRC Press, Boca Raton.

Susanto, A., Herjayanto, M., Alimudin, Budiaji, W., Priyantono, E., Guna, N.A. (2021). The development design of venturi type protein skimmer for mariculture land base system. The $2^{\text {nd }}$ International Conference on Agriculture and Rural Development. IOP Conf. Series: Earth and Environmental Science, 715, 012063. https://doi.org/10.1088/1755-1315/715/1/012063

Tamhankar, N., Pandhare, A., Joglekar, A., \& Bansode, V. (2014). Experimental and CFD analysis of flow through venturi meter to determine the coefficient of discharge. International Journal of Latest Trends in Engineering and Technology, 3(4), 194-200.

Taricska, J.R., Hung, Y.T., \& Li, K.H. (2008). Submerged aeration. In: N. Shammas, ed. Handbook of Environmental Engineering, Volume 8: Biological Treatment Processes. Totowa, NJ: Humana Press, pp. 818.

Tchobanoglous, G., \& Kreith, F. (2002). Handbook of solid waste management. $2^{\text {nd }}$ ed., McGraw Hill Handbooks, New York.

Tukimin, A., Zuber, M., \& Ahmad, K.A. (2016). CFD analysis of flow through venturi tube and its discharge coefficient. IOP Conf. Series: Materials Science and Engineering, 152, 012-062. 10.1088/1757-899X/152/1/012062

Wang, X., \& Zhang, Y. (1999). Development of a critical airflow venturi for air sampling. Journal Agricultural Engineering and Resource, 73(3), 257-264. 10.1088/1757899X/152/1/012062

West, H. (2009). Apparatus and method for introducing a gas into a liquid - GB 2471280 A, London: UK Patent Application.

Xu, X., Wei, W., Liu, F., Wei, W., \& Liu, Z. (2020). Experimental study on aeration efficiency in a pilot-scale decelerated oxidation ditch equipped with fine bubble diffusers and 
impellers. The Canadian J Chem Eng, 1-11. https://doi.org/10.1002/cjce.23919

Yadav, A., Kumar, A., \& Sarkar, S. (2021). Performance evaluation of venturi aeration system. Aquacultural Engineering, 93, 102156.

https://doi.org/10.1016/j.aquaeng.2021.102156

Yin, Z., Feng, Y., Wang, Y., Gao, C., \& Ma, N. (2018). 3-D Numerical investigation on oxygen transfer in a horizontal venturi flow with two holes. Water, 10(174), 1-13. 10.3390/w10020174

Zhang, C., Song, B., Shan, J., Ni, Q., Wu, F., \& Wang, S. (2020). Design and optimization of a new tube aeration device. Aquaculture International, 28, 985-999. https://doi.org/10.1007/s10499-020-00507-2

Zhang, J.X. (2017). Analysis on the effect of venturi tube structural parameters on fluid flow. AIP Advances, 7, 065315. https://doi.org/10.1063/1.4991441 